
\title{
28 Research Square \\ Tropical volcanism enhanced the East Asian summer monsoon during the last millennium
}

Fei Liu

Sun Yat-Sen University https://orcid.org/0000-0001-9223-0011

Chaochao Gao ( $\nabla$ gaocc@zju.edu.cn )

Zhejiang University https://orcid.org/0000-0002-0414-3477

Jing Chai

Chengdu University of Information Technology

Alan Robock

Rutgers University https://orcid.org/0000-0002-6319-5656

\section{Bin Wang}

University of Hawaii at Manoa

Jinbao Li

University of Hong Kong https://orcid.org/0000-0002-8919-4715

\section{Xu Zhang}

State Key Laboratory of Tibetan Plateau Earth System, Resources and Environment (TPESRE), Institute of Tibetan Plateau Research, Chinese Academy of Sciences https://orcid.org/0000-0003-1833-9689

\section{Gang Huang}

Institute of Atmospheric Physics, Chinese Academy of Sciences https://orcid.org/0000-0002-86927856

\section{Wenjie Dong}

Sun Yat-sen University

\section{Article}

Keywords:

Posted Date: December 2nd, 2021

DOI: https://doi.org/10.21203/rs.3.rs-1083868/v1

License: (c) (i) This work is licensed under a Creative Commons Attribution 4.0 International License. Read Full License 
Version of Record: A version of this preprint was published at Nature Communications on June 14th, 2022. See the published version at https://doi.org/10.1038/s41467-022-31108-7. 


\section{Abstract}

Extreme East Asian summer monsoon (EASM) rainfall frequently induces floods that pose threats to millions of people across East Asia. The intensified EASM rainfall has been generally attributed to internal modes of climate variability, while external volcanic forcing has been suggested to suppress the EASM. In contrast to the hydrological weakening theory of volcanic eruptions, we present convergent empirical and modeling evidence for significant intensification of EASM rainfall in response to strong tropical volcanic eruptions. Our paleoclimate proxy analyses show a significantly increased EASM in the first summer after large tropical eruptions from 1470 AD to the present. The multi-proxy ensemble mean demonstrates that the occurrence of an El Niño in the first boreal winter after a volcanic eruption is necessary for the enhanced EASM. The results from the last-millennium climate model simulations show that a volcano-induced El Niño and the associated warm pool air-sea interaction intensify EASM precipitation, overwhelming volcanic-induced moisture deficiency. This work offers a new perspective on the intertwined relationship between external forcing and internal variability in the complex climate system and potential flood disasters resulting from tropical volcanic eruption.

\section{Main}

The record-breaking EASM rainfall in 2020 caused a humanitarian disaster, affecting 45.4 million people in China and resulting in over 142 human casualties and more than 16 billion US dollars economic loss ${ }^{1}$. EASM rainfall is usually enhanced by moisture advection and convergence of southwesterly monsoon over the northwest flank of the western North Pacific subtropical high, following an El Niño peak in the previous winter ${ }^{2-6}$. A recent study ${ }^{7}$ also proposed that El-Niño-related tropical tropospheric warming could shift the westerlies southward, which would impinge on the Tibetan Plateau and induce northerlies downstream of the plateau to intensify the East Asian rainband.

Large volcanic eruptions are one of the major natural external forcings of Earth's climate variability from interannual to centennial time scales ${ }^{8,9}$. The EASM is found to be suppressed after volcanic eruptions in model simulations ${ }^{10-12}$ due to the reduction of surface shortwave radiation and associated slowdown of the global hydrological cycle $\mathrm{e}^{13-16}$. Volcanic eruptions have been suggested as the cause of some historical drought events ${ }^{17,18}$. However, no significant drought was recorded in the Chinese chronicles following the large 1815 Tambora eruption ${ }^{19}$, nor in observations following the 1982 El Chichón and 1991 Pinatubo eruptions ${ }^{20}$. These case studies raise a question about the perception of monsoon suppression by volcanic perturbations.

Previous studies of the effects of volcanic eruptions on EASM commonly overlook the role of El Niño, although it has been suggested by a number of proxy-reconstructed El Niño/Southern Oscillation (ENSO) indices that the likelihood of an El Niño increases after eruptions ${ }^{21-27}$. Several mechanisms have been proposed using state-of-the-art model simulations to explain this connection: the ocean dynamic 
thermostat ${ }^{28-30}$, land-sea thermal contrast ${ }^{31-33}$, and equatorward migration of the Intertropical Convergence Zone ${ }^{34-36}$.

This work investigates the response of the EASM-tropical Pacific system to tropical volcanism to understand the interaction and relative roles of internal climate feedback and external forcing. We analyze long-term multi-proxy data and multi-model simulations and find that the volcano-induced El Niño and the associated warm pool air-sea interaction can intensify the EASM precipitation, overshadowing the hydrological weakening of volcanic eruptions.

We first examined the EASM-tropical Pacific response to 22 precisely dated tropical large volcanic eruptions $^{37}$ for the period from 1470 to 1999 AD using the gridded precipitation proxy data ${ }^{38}$ and the ensemble mean of 11 sets of ENSO paleoclimate reconstructions (see Methods).

The composite results of East Asian rainfall reconstruction in the first post-eruption summer show significant (at the $90 \%$ confidence level) positive precipitation anomalies centered around the Yangtze River basin, northeast China, and Kyushu of Japan, accompanied by negative, albeit not significant, anomalies over the Indo-China Peninsula and the Philippines (Fig. 1a). This meridional dipole precipitation anomaly pattern resembles the enhanced EASM-Pacific High response in the first post-El Niño summer that is well observed with instrumental observations ${ }^{2,4,5}$. Enhanced EASM precipitation in the first post-eruption summer is also observed in two other well-known precipitation reconstructions over $\mathrm{China}^{39}$ and over all of $\mathrm{Asia}^{40}$ (Supplementary Fig. S1). The relatively lower confidence level in the latter may be related to the point-by-point regression methods used. Significant positive EASM $\left(25^{\circ}-34^{\circ} \mathrm{N}\right.$, $106^{\circ}-122^{\circ} \mathrm{E}$ ) precipitation anomalies (at the $95 \%$ confidence level), mainly over the middle-lower reach of the Yangtze River, are only observed in the first boreal summer after the eruption (Fig. 1b). Our multi-proxy analysis results thus indicate that explosive tropical eruptions tend to increase EASM rainfall in the first subsequent boreal summer, suggesting quick monsoon-ocean feedback after large tropical eruptions.

The ensemble mean of 11 available ENSO reconstructions indicates a significant post-eruption precipitation increase following an El Niño (Fig. 2a), in contrast to the normal EASM precipitation anomalies after an eruption without a preceding El Niño (Fig. 2b). Significantly negative anomalies, on the other hand, are observed over the Indo-China Peninsula, Taiwan, and the Philippines, demonstrating compelling evidence for an El Niño-enhanced Pacific High and its role in modulating the volcanic-induced EASM response.

Next, we investigated the last-millennium climate simulation results of 13 different models from the Paleoclimate Modeling Intercomparison Project phases 3 and 4 (PMIP3 \& PMIP4) and from additional Community Earth System Model (CESM) last-millennium ensembles, to interpret the monsoon-ocean response to tropical large volcanic eruptions in the context of current state-of-the-art models. Based on the actual volcanic forcing used in each model, the 13 simulations amount to 92 eruption events for the common pre-industrial period from 1470 to 1849 AD, and they were used to construct a superposed epoch analysis (see Methods). The average of these 92 eruption simulations shows Indo-Pacific oceanic 
cooling and Asian drying in the first post-eruption summer, and maximum drying is found over the western Indo-China peninsula (Fig. 3a). Positive precipitation anomalies are simulated over the middlelower reach of the Yangtze River but are significant only in a small area. The associated EASM circulation index, defined by the lower-tropospheric zonal wind shear vorticity of the enhanced Pacific High (see Methods), exhibits a significantly negative anomaly, demonstrating an enhanced EASM circulation in the multi-model ensemble mean results (Fig. 3a).

The responses of EASM precipitation to the direct volcanic forcing and to an EI Niño can be differentiated by comparing two sets of composites with or without the preceding El Niño among the 92 events. The composite for 68 out of the 92 events without a preceding El Niño mainly exhibits a direct cooling and drying volcanic effect over most parts of the globe. The entire Asian region is dominated by negative precipitation anomalies (Fig. 3b). The relative El Niño signal, the eastward gradient of equatorial Pacific sea surface temperature (SST) anomaly arguably excited by the tropical volcanic eruption ${ }^{27,32}$, is simulated, accompanied by significant equatorial westerly anomalies over the eastern Pacific and easterly anomalies over the Indian Ocean, while there is no significantly enhanced Pacific High. In contrast, in the presence of a preceding El Niño, the model results show increased post-eruption summer precipitation in the EASM region, and the most significant enhancement is located over the lower reach of the Yangtze River, driven by the convergence and moisture advection of southwesterly wind anomalies of the enhanced Pacific High and extratropical northerly anomalies, albeit not significant, downstream of the Tibetan Plateau (Fig. 3c). This El Niño-increased EASM precipitation after volcanic eruptions is also simulated when considering all 228 eruption events during the last millennium covering 850-1849 AD in all 13 PMIP models (Supplementary Fig. S2).

Ten CESM last-millennium ensemble simulations from 850 to 2005 AD provide us an opportunity to study the overlapping period of 1470-1999 AD with the paleoclimate reconstructions. CESM has good performance in simulating ENSO seasonality, amplitude, frequency, and teleconnection ${ }^{41}$. The results derived from all available eruption events from 1470-1999 in 10 CESM last-millennium ensembles confirm the critical role of El Niño after volcanic eruptions in increasing EASM precipitation (Figs. 3d-3f).

Among the 92 eruption events, the post-eruption EASM precipitation change is significantly correlated with the preceding El Niño ( 0.21 , at the $95 \%$ confidence level) two seasons before, and the correlation is higher for the EASM circulation (-0.39, at the $99 \%$ confidence level) than for the precipitation. This is because the EASM circulation index, i.e., the Pacific High, is better captured by numerical models than precipitation ${ }^{42}$. These significant relations indicate that a stronger El Niño tends to induce a larger EASM increase, consistent with the instrumental observations ${ }^{43}$.

After a preceding El Niño, strong negative precipitation anomalies are simulated over South Asia, consistent with previous studies demonstrating the drying effect of large volcanic eruptions on the South Asian monsoon ${ }^{44}$. The enhanced Pacific high is tied to the SST cooling to its southeast in both PMIPs and CESM simulations (Figs. 3c and 3f), explained by the wind-evaporation SST feedback after an El Niño ${ }^{4}$. Easterly wind anomalies over the North Indian Ocean, which was also suggested to increase the 
Pacific High ${ }^{5}$, are only significant over the Arabian Sea. In CESM last-millennium ensembles, however, the significant easterly wind anomalies are simulated over North Indian Ocean, coupled with western Indian Ocean warming.

The change of monsoon precipitation can be divided into dynamic and thermodynamic causes ${ }^{45}$, which are related to the changes in circulation and moisture availability, respectively (see Methods). After a volcanic eruption, dynamics-related precipitation is increased while the thermodynamics-related precipitation is decreased, demonstrating the volcanic-induced cooling and drying (Fig. 4). The decreased thermodynamics-induced precipitation counteracts the increased dynamically-induced precipitation, resulting in a weak change in total precipitation. The presence of an El Niño tends to enhance the dynamics-related precipitation, while keeping the thermodynamics-related precipitation almost intact (Fig. 4). Results from these last-millennium experiments confirm the critical role of a preceding El Niño in enhancing the EASM, against the well-known cooling and hydrological weakening effect of volcanic eruptions $^{13-16}$.

The fraction of El Niño occurring after volcanic eruptions in reconstructions is $41 \%$ from 1470 to 1999 AD (Fig. 2), larger than the expected percentage (27\%) for internal El Niño events without the volcanic effect. This explains why the composite EASM rainfall after all eruptions is increased in reconstructions. In the models, this count fraction is only $26 \%$ for PMIPs or $32 \%$ for CESM (Fig. 3), resulting in a feeble EASM rainfall increase in the all-eruption case. This less frequent occurrence of El Niño, against a robust equatorial Pacific westerly response to tropical volcanic eruptions, was argued to be caused by weak coupling between central Pacific precipitation and westerly anomalies in current models ${ }^{46}$.

To conclude, this work finds an east-west asymmetric monsoonal-ocean response to the zonally symmetric volcanic forcing, highlighting the delayed oceanic responses to volcanic eruptions in exciting EASM precipitation change. The precipitation increase due to wind convergence induced by the enhanced western North Pacific high overwrites the precipitation reduction due to the thermodynamically induced moisture deficiency. The tropical Pacific plays a critical role in modulating the climate system response to external forcing. Similar cases are found in the Nuclear $\mathrm{Niño}^{33}$ or the northern Eurasia winter warming responses to stratospheric soot and sulfate aerosols injections during volcanic scenarios ${ }^{47}$. Moreover, current paleoclimate reconstructions exhibit divergent ENSO responses to volcanic eruptions ${ }^{21,27,48}$. Five out of the 11 ENSO reconstructions show a significant El Niño response to the volcanic eruptions, as did the ensemble mean (Supplementary Fig. S3). Our results provide indirect but strong evidence for the increased post-eruption EI Niño occurrence because without such a response the EASM precipitation could not be enhanced against the volcanic cooling and drying effect.

\section{Declarations}

Acknowledgments: F.L. is supported by the National Natural Science Foundation of China (Grant 41975107). C.G. is supported by the National Natural Science Foundation of China 
(Grant 41875092). A.R. is supported by U.S. National Science Foundation grant AGS-2017113. B. W. acknowledges support from National Science Foundation grant 2025057.

Author contributions: F.L., C.G., and B.W. conceptualized and led the work. F.L., C.G., and J.C. contributed to data analysis including validation and interpretation of the results. F.L., C.G., and B.W. wrote the manuscript, and all authors reviewed and edited the manuscript.

Additional information: Supplementary information is available in the online version of the paper. Reprints and permissions information is available online at www.nature.com/reprints. Correspondence and requests for materials should be addressed to C.G.

Competing financial interests: The authors declare no competing financial interests.

\section{References}

1. Wei, K. et al. Reflections on the catastrophic 2020 Yangtze River basin flooding in southern China. The Innovation 1, 100038, doi:http://doi.org/10.1016/j.xinn.2020.100038 (2020).

2. Zhang, R., Sumi, A. \& Kimoto, M. A diagnostic study of the impact of El Niño on the precipitation in China. Adv. Atmos. Sci. 16, 229-241, doi:https://doi.org/10.1007/BF02973084 (1999).

3. Chang, C.-P., Zhang, Y. \& Li, T. Interannual and interdecadal variations of the East Asian summer monsoon and tropical Pacific SSTs. Part II: Meridional structure of the monsoon. J. Climate 13, 4326-4340, doi:http://doi.org/10.1175/1520-0442(2000)013<4326:laivot>2.0.Co;2 (2000).

4. Wang, B., Wu, R. \& Fu, X. Pacific-East Asian teleconnection: How does ENSO affect East Asian climate? J. Climate 13, 1517-1536, doi:http://doi,org/10.1175/15200442(2000)013<1517:Peathd>2.0.Co;2 (2000).

5. Xie, S. et al. Indian Ocean capacitor effect on Indo-western Pacific climate during the summer following El Niño. J. Climate 22, 730-747, doi:http://doi.org/10.1175/2008jcli2544.1 (2009).

6. Takaya, Y., Kosaka, Y., Watanabe, M. \& Maeda, S. Skilful predictions of the Asian summer monsoon one year ahead. Nat. Commun. 12, 2094, doi:https:/doi.org/10.1038/s41467-021-22299-6 (2021).

7. Kong, W. \& Chiang, J. C. H. Southward shift of westerlies intensifies the East Asian early summer rainband following El Niño. Geophys. Res. Lett. 47, e2020GL088631, doi:https://doi.org/10.1029/2020GL088631 (2020).

8. Robock, A. Volcanic eruptions and climate. Reviews of Geophysics 38, 191-219, doi:https://doi.org/10.1029/1998RG000054 (2000).

9. Mann, M., Steinman, B., Brouillette, D. \& Miller, S. Multidecadal climate oscillations during the past millennium driven by volcanic forcing. Science 371, 1014-1019, doi:http://doi.org/10.1126/science.abc5810 (2021).

10. Man, W., Zhou, T. \& Jungclaus, J. H. Effects of large volcanic eruptions on global summer climate and East Asian monsoon changes during the last millennium: Analysis of MPI-ESM Simulations. J. Climate 27, 7394-7409, doi:http://doi.org/10.1175/jcli-d-13-00739.1 (2014). 
11. Wegmann, M. et al. Volcanic influence on European summer precipitation through monsoons: Possible cause for "Years without Summer". J. Climate 27, 3683-3691, doi:http://doi.org/10.1175/jcli-d-13-00524.1 (2014).

12. Peng, Y., Cheng, H., Chen, K. \& Huang, S. Modeling study of severe persistent drought events over Eastern China during the last millennium. Quat. Sci. 39, 282-293 (2019).

13. Trenberth, K. E. \& Dai, A. Effects of Mount Pinatubo volcanic eruption on the hydrological cycle as an analog of geoengineering. Geophys. Res. Lett. 34, doi:https://doi.org/10.1029/2007GL030524 (2007).

14. Schneider, D. P., Ammann, C. M., Otto-Bliesner, B. L. \& Kaufman, D. S. Climate response to large, highlatitude and low-latitude volcanic eruptions in the Community Climate System Model. J. Geophys. Res. Atmos. 114, doi:https://doi.org/10.1029/2008JD011222 (2009).

15. Joseph, R. \& Zeng, N. Seasonally modulated tropical drought induced by volcanic aerosol. J. Climate 24, 2045-2060, doi:http://doi.org/10.1175/2009jcli3170.1 (2011).

16. Iles, C. E., Hegerl, G. C., Schurer, A. P. \& Zhang, X. The effect of volcanic eruptions on global precipitation. J. Geophys. Res. Atmos. 118, 8770-8786, doi:https://doi.org/10.1002/jgrd.50678 (2013).

17. Shen, C., Wang, W.-C., Hao, Z. \& Gong, W. Exceptional drought events over eastern China during the last five centuries. Clim. Change 85, 453-471, doi:http://doi.org/7/s10584-007-9283-y (2007).

18. Shen, C., Wang, W.-C., Hao, Z. \& Gong, W. Characteristics of anomalous precipitation events over eastern China during the past five centuries. Climate Dyn. 31, 463-476, doi:http://doi.org/10.1007/s00382-007-0323-0 (2008).

19. Gao, C., Gao, Y., Zhang, Q. \& Shi, C. Climatic aftermath of the 1815 Tambora eruption in China. J. Meteorol. Res. 31, 28-38, doi:http://doi.org/10.1007/s13351-017-6091-9 (2017).

20. Liu, Y., Li, Y. \& Jia, P. A Comparative analysis of effect of volcanic eruptions at low and mid-high latitudes on drought/flood in China. Meteor. Monthly 19, 3-7 (1993).

21. Adams, J., Mann, M. E. \& Ammann, C. M. Proxy evidence for an El Niño-like response to volcanic forcing. Nature 426, 274-278, doi:http://doi.org/10.1038/nature02101 (2003).

22. D'Arrigo, R., Wilson, R. \& Tudhope, A. The impact of volcanic forcing on tropical temperatures during the past four centuries. Nat. Geosci. 2, 51-56, doi:http://doi.org/10.1038/ngeo393 (2009).

23. McGregor, S., Timmermann, A. \& Timm, O. J. C. o. t. P. A unified proxy for ENSO and PDO variability since 1650. Clim. Past 6, 1-17, doi:https://doi.org/10.5194/cp-6-1-2010 (2010).

24. Wilson, R. et al. Reconstructing ENSO: the influence of method, proxy data, climate forcing and teleconnections. J. Quat. Sci. 25, 62-78, doi:https://doi.org/10.1002/jqs.1297 (2010).

25. Liu, F. et al. Divergent El Niño responses to volcanic eruptions at different latitudes over the past millennium. Climate Dyn. 50, 3799-3812, doi:http://doi.org/10.1007/s00382-017-3846-z (2018).

26. McGregor, S. et al. The effect of strong volcanic eruptions on ENSO. In El Niño Southern Oscillation in a Changing Climate (pp. 267- 287). American Geophysical Union (AGU), 
doi:https://doi.org/10.1002/9781119548164.ch12 (2020).

27. Robock, A. Comment on "No consistent ENSO response to volcanic forcing over the last millennium". Science 369, doi:http://doi.org/10.1126/science.abc0502 (2020).

28. Mann, M. E., Cane, M. A., Zebiak, S. E. \& Clement, A. Volcanic and solar forcing of the tropical pacific over the past 1000 years. J. Climate 18, 447-456, doi:http://doi.org/10.1175/jcli-3276.1 (2005).

29. Maher, N., McGregor, S., England, M. H. \& Gupta, A. S. Effects of volcanism on tropical variability. Geophys. Res. Lett. 42, 6024-6033, doi:https://doi.org/10.1002/2015GL064751 (2015).

30. Predybaylo, E., Stenchikov, G. L., Wittenberg, A. T. \& Zeng, F. Impacts of a Pinatubo-size volcanic eruption on ENSO. Proc. Natl. Acad. Sci. 122, 925-947, doi:https://doi.org/10.1002/2016JD025796 (2017).

31. Ohba, M., Shiogama, H., Yokohata, T. \& Watanabe, M. Impact of strong tropical volcanic eruptions on ENSO simulated in a coupled GCM. J. Climate 26, 5169-5182, doi:http://doi.org/10.1175/jcli-d-1200471.1 (2013).

32. Khodri, M. et al. Tropical explosive volcanic eruptions can trigger El Niño by cooling tropical Africa. Nat. Commun. 8, 778, doi:http://doi.org/10.1038/s41467-017-00755-6 (2017).

33. Coupe, J. et al. Nuclear Niño response observed in simulations of nuclear war scenarios. Commun. Earth Environ. 2, 18, doi:http://doi,org/10.1038/s43247-020-00088-1 (2021).

34. Pausata, F. S., Chafik, L., Caballero, R. \& Battisti, D. S. Impacts of high-latitude volcanic eruptions on ENSO and AMOC. Proc. Natl. Acad. Sci. USA 112, 13784-13788, doi:http://doi.org/10.1073/pnas.1509153112 (2015).

35. Lim, H.-G. et al. Threshold of the volcanic forcing that leads the El Niño-like warming in the last millennium: results from the ERIK simulation. Climate Dyn. 46, 3725-3736, doi:http://doi.org/10.1007/s00382-015-2799-3 (2016).

36. Stevenson, S., Otto-Bliesner, B., Fasullo, J. \& Brady, E. "El Niño Like” hydroclimate responses to last millennium volcanic eruptions. J. Climate 29, 2907-2921, doi:http://doi.org/10.1175/jcli-d-15-0239.1 (2016).

37. Sigl, M. et al. Timing and climate forcing of volcanic eruptions for the past 2,500 years. Nature $\mathbf{5 2 3}$, 543-549, doi:http://doi.org/10.1038/nature14565 (2015).

38. Feng, S., Hu, Q., Wu, Q. \& Mann, M. E. A gridded reconstruction of warm season precipitation for Asia spanning the past half millennium. J. Climate 26, 2192-2204, doi:http://doi.org/10.1175/jcli-d-1200099.1 (2013).

39. Shi, F., Zhao, S., Guo, Z., Goosse, H. \& Yin, Q. Multi-proxy reconstructions of May-September precipitation field in China over the past 500 years. Clim. Past 13, 1919-1938, doi:http://doi.org/10.5194/cp-13-1919-2017 (2017).

40. Shi, H., Wang, B., Cook, E. R., Liu, J. \& Liu, F. Asian summer precipitation over the past 544 years reconstructed by merging tree rings and historical documentary records. J. Climate 31, 7845-7861, doi:http://doi.org/10.1175/jcli-d-18-0003.1 (2018). 
41. Bellenger, H., Guilyardi, E., Leloup, J., Lengaigne, M. \& Vialard, J. ENSO representation in climate models: from CMIP3 to CMIP5. Climate Dyn. 42, 1999-2018, doi:http://doi.org/10.1007/s00382-0131783-z (2014).

42. Wang, B., Xiang, B. \& Lee, J.-Y. Subtropical High predictability establishes a promising way for monsoon and tropical storm predictions. Proc. Natl. Acad. Sci. 110, 2718-2722, doi:http://doi.org/10.1073/pnas.1214626110 (2013).

43. Wang, B., Li, J. \& He, Q. Variable and robust East Asian monsoon rainfall response to El Niño over the past 60 years (1957-2016). Adv. Atmos. Sci. 34, 1235-1248, doi:http://doi.org/10.1007/s00376017-7016-3 (2017).

44. Singh, M. et al. Fingerprint of volcanic forcing on the ENSO-Indian monsoon coupling. Sci. Adv. 6, eaba8164, doi:http://doi.org/10.1126/sciadv.aba8164 (2020).

45. Liu, F. et al. Global monsoon precipitation responses to large volcanic eruptions. Sci. Rep. 6, 24331, doi:10.1038/srep24331 (2016).

46. Chai, J. et al. A robust equatorial Pacific westerly response to tropical volcanism in multiple models. Climate Dyn. 55, 3413-3429, doi:http://doi.org/10.1007/s00382-020-05453-6 (2020).

47. Coupe, J. \& Robock, A. The influence of stratospheric soot and sulfate aerosols on the Northern Hemisphere wintertime atmospheric circulation. J. Geophys. Res. Atmos. 126, e2020JD034513, doi:https://doi.org/10.1029/2020JD034513 (2021).

48. Dee, S. et al. No consistent ENSO response to volcanic forcing over the last millennium. Science 367, 1477-1481, doi:http://doi.org/10.1126/science.aax2000 (2020).

49. Duchon, C. E. Lanczos filtering in one and two dimensions. J. Appl. Meteorol. Climatol. 18, 10161022, doi:http://doi.org/10.1175/1520-0450(1979)018<1016:LFIOAT>2.0.CO;2 (1979).

50. Rayner, N. A. et al. Global analyses of sea surface temperature, sea ice, and night marine air temperature since the late nineteenth century. J. Geophys. Res. Atmos. 108, 4407, doi:https://doi.org/10.1029/2002JD002670 (2003).

51. Wang, B. \& Fan, Z. Choice of South Asian summer monsoon indices. Bull. Amer. Meteor. Soc. 80, 629-638, doi:http://doi.org/10.1175/1520-0477(1999)080<0629:Cosasm>2.0.Co;2 (1999).

\section{Methods}

Proxy data. The proxy data we analyzed mainly include a long-term reconstruction of Asian summer precipitation ${ }^{38}$ and 11 reconstructed ENSO indices (Supplementary Table S1). The Feng, et al. ${ }^{38}$ data are a gridded $\left(0.5^{\circ} \times 0.5^{\circ}\right)$ reconstruction of annual May-September precipitation from 1470 to $1999 \mathrm{AD}$ over the whole Asian continent and are mainly based on 500-year historical documentary records, tree-ring data, ice-core records, and a few long-term instrumental data series. A regional empirical orthogonal function method is utilized to increase the signal-to-noise ratio. Two other gridded reconstructions of precipitation based on point-by-point regression methods are also analyzed in parallel, serving as confirmation of the results: a 530-yr multi-proxy May-September precipitation reconstruction over China 
$\left(0.5^{\circ} \times 0.5^{\circ}\right)$ based on the tree-ring chronologies and drought/flood indices from 1470 to $2000 \mathrm{AD}^{39}$, and an annual June-August rainfall reconstruction over the Asian land region $\left(2^{\circ} \times 2^{\circ}\right)$ generated by merging 453 tree-ring width chronologies and 71 historical documentary records from 1470 to $2013^{40}$.

To test the potential role of a preceding El Niño on volcanic-induced EASM rainfall change, the ensemble mean of 11 available ENSO indices is reconstructed and applied, following the method used before ${ }^{25}$ except adding one new proxy ${ }^{48}$. All of the 11 ENSO indices first go through a 9-yr Lanczos high-pass filter ${ }^{49}$ to isolate the ENSO signal, and then are normalized according to their own standard deviations. The ensemble mean is utilized to remove proxy uncertainty. Since these 11 indices cover different periods, with the longest extending from 900 to $2002 A D$ and the shortest from 1706 to $1997 A D$, the ensemble mean for each year from 1470 to 1999 AD is calculated as the average of available indices. The resulting ensemble mean has a high correlation with instrumental December-February Niño 3.4 index of 0.83 (at the $99 \%$ confidence level) for the period of $1871-1999$, based on the averaged $\left(5^{\circ} \mathrm{N}-5^{\circ} \mathrm{S}\right.$, $\left.120^{\circ}-170^{\circ} \mathrm{W}\right) \mathrm{SST}$ anomaly from Hadley Centre Ice and SST version 1 (HadISST 1$)^{50}$.

All 22 tropical eruptions from the Sigl, et al. ${ }^{37}$ volcanic reconstruction during the period of 1470-1999 AD, when Asian precipitation proxies are available, are used for the composite analysis. We define the peak aerosol loading year as the eruption year 0 (Supplementary Table S2).

Last-millennium simulations. All of the 10 last-millennium climate simulations in the PMIP3; and three simulations in the PMIP4, with additional outputs from CESM's 10 last-millennium all forcing simulations (Supplementary Table S3), are analyzed in order to understand the underlying mechanism of observed EASM response to large volcanic eruptions. Since different volcanic forcing reconstructions are used in the last-millennium simulations from PMIP models and CESM (Supplementary Table S3), the accuracy of the eruption date and strength in each last-millennium simulation is determined according to the volcanic forcing used, and year 0 denotes the year with maximum annual-mean stratospheric sulfate aerosol injection for each eruption, consistent with the using of peak aerosol loading year in reconstruction analysis ${ }^{37}$. In PMIP3 and CESM, the tropical and high-latitude eruptions are not precisely named, thus the eruption type is determined based on the meridional distribution of the aerosol density or aerosol optical depth. A tropical eruption is defined when its maximum aerosol forcing is in the tropics ${ }^{45}$. Since the PMIP simulations only cover the pre-industrial period before 1850, we have 92 eruption events in the 13 PMIP model simulations for period of 1470-1849 AD and 228 events for the whole last millennium of 850-1849 $A D$, listed in Supplementary Table S4. In the 10 full forcing ensembles of CESM we have 90 eruption events for the period of 1470-1999 AD when the Asian precipitation reconstructions are available.

Composite and significance. A superposed epoch analysis ${ }^{21}$ is used to evaluate the influence of explosive tropical volcanoes on global cooling and related EASM-ocean interaction. To isolate the climate responses to an eruption from the background noise, we obtain the anomaly by removing the climatology of the five years preceding the eruption. We apply the superposed epoch analysis to the reconstructed EASM precipitation and Niño 3.4 indices based on the 22 reconstructed tropical eruptions, and internal 
variability is expected to be filtered out. The superposed epoch analysis is also performed on multi-model simulations from PMIP3 and PMIP4 and on multi-ensemble simulations from CESM. Significance of the superposed epoch analysis results for the 11-year window of five years before and six years after each eruption is calculated by the bootstrapped resampling method with 10,000 random draws from the study period $^{21}$.

Climate indices and variability. The Niño 3.4 index is defined as the area-averaged SST anomaly over the area $\left(5^{\circ} \mathrm{N}-5^{\circ} \mathrm{S}, 120^{\circ}-170^{\circ} \mathrm{W}\right)$. To use the same standard for selecting the El Niño event list among reconstructions with different scales, an El Niño event is defined when the boreal winter Niño 3.4 index is greater than 0.5 standard deviations in both reconstructions and simulations. Using different thresholds to select El Niño events does not change our results qualitatively. Boreal summer is defined as MaySeptember, and boreal winter, as December-February, consistent with those used for reconstructions. The EASM region is defined as the region over $\left(25^{\circ}-34^{\circ} \mathrm{N}, 106^{\circ}-122^{\circ} \mathrm{E}\right)$ in both reconstructions and simulations. Based on the simulated western North Pacific subtropical high, the EASM circulation index is defined as the 850 -hPa zonal wind difference between the northern $\left(22^{\circ}-32^{\circ} \mathrm{N}, 130^{\circ}-160^{\circ} \mathrm{E}\right)$ and southern $\left(9^{\circ}-19^{\circ} \mathrm{N}, 120^{\circ}-150^{\circ} \mathrm{E}\right)$ regions, a little different from the original index between northern $\left(22.5^{\circ}-32.5^{\circ} \mathrm{N}, 110^{\circ}-140^{\circ} \mathrm{E}\right)$ and southern $\left(5^{\circ}-15^{\circ} \mathrm{N}, 90^{\circ}-130^{\circ} \mathrm{E}\right)$ regions from instrumental observations ${ }^{51}$.

The monsoon precipitation index can be represented by moisture convergence ${ }^{45}$, such as

$$
P^{\prime}=-\left(\bar{q} \omega^{\prime}+q^{\prime} \bar{\omega}+q^{\prime} \omega^{\prime}\right)
$$

where q denotes surface specific humidity and $\omega$ is the pressure velocity at $500 \mathrm{hPa}$. The overbar denotes the mean state before the eruption, while the prime, the anomaly after the eruption. $\bar{q} \omega^{\prime}$ and $q^{\prime} \bar{\omega}$ denote the dynamic and thermodynamic related precipitation changes, respectively. $q^{\prime} \omega^{\prime}$ nonlinear feedback and is usually much smaller than the dynamic or thermodynamic counterparts.

\section{Figures}



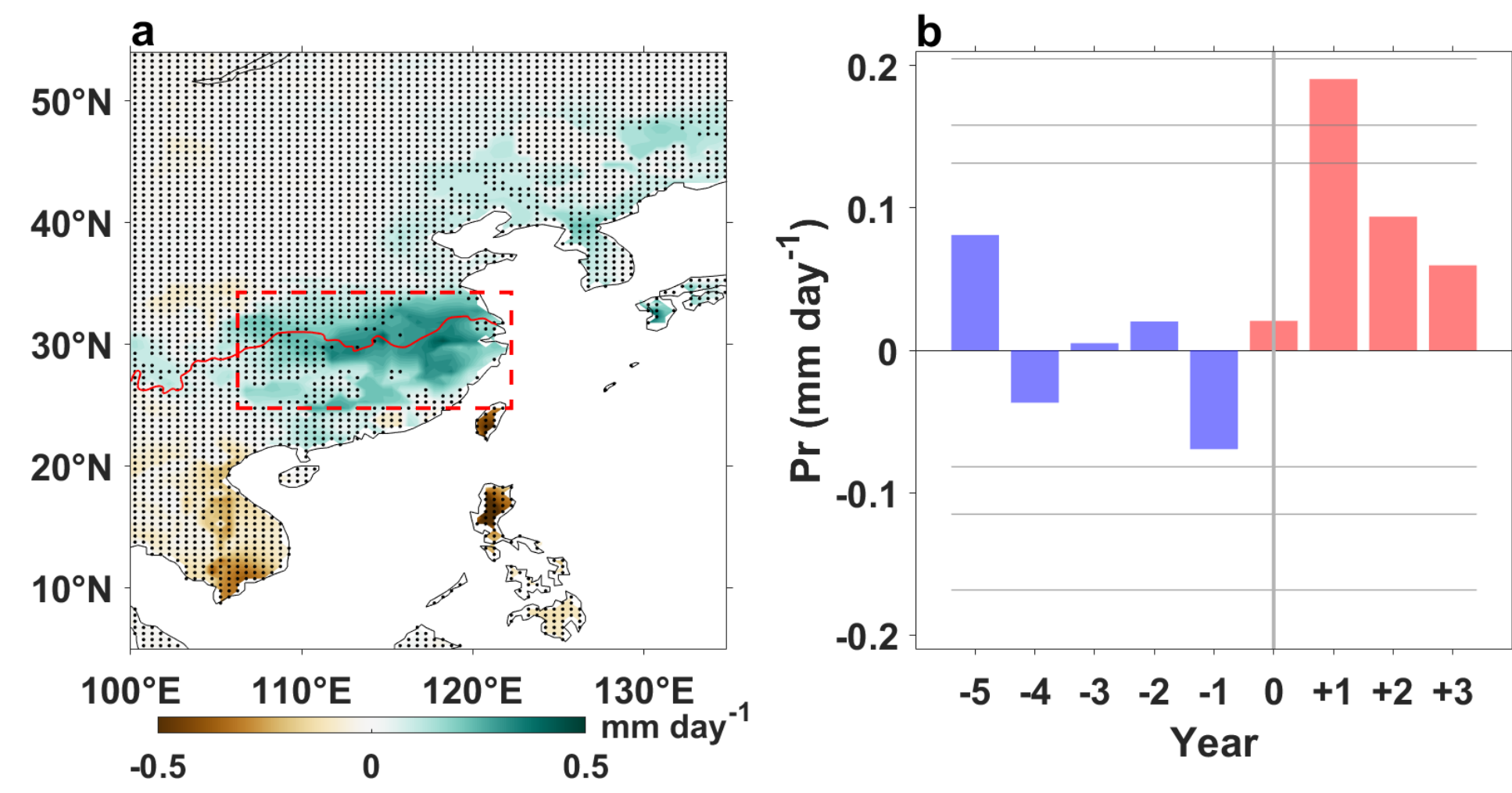

Figure 1

East Asian summer monsoon (EASM) response to tropical eruptions based on reconstructions. a Superposed epoch analysis results of East Asian precipitation anomalies (shading) in the first boreal summer after 22 tropical eruptions from 1470 to 1999 AD. Stippling indicates precipitation anomalies not significant at the $90 \%$ confidence level. The red curve is the Yangtze River, and the red box indicates the EASM region $\left(106^{\circ}-122^{\circ} \mathrm{E}, 2^{\circ}-34^{\circ} \mathrm{N}\right)$. b Composite EASM-averaged precipitation anomaly for 22 tropical eruptions. Confidence limits (90\%, 95\%, 99\%) are marked by horizontal lines. Red and blue colors mark the post-eruption and pre-eruption composites, respectively. Year 0 denotes the eruption year.
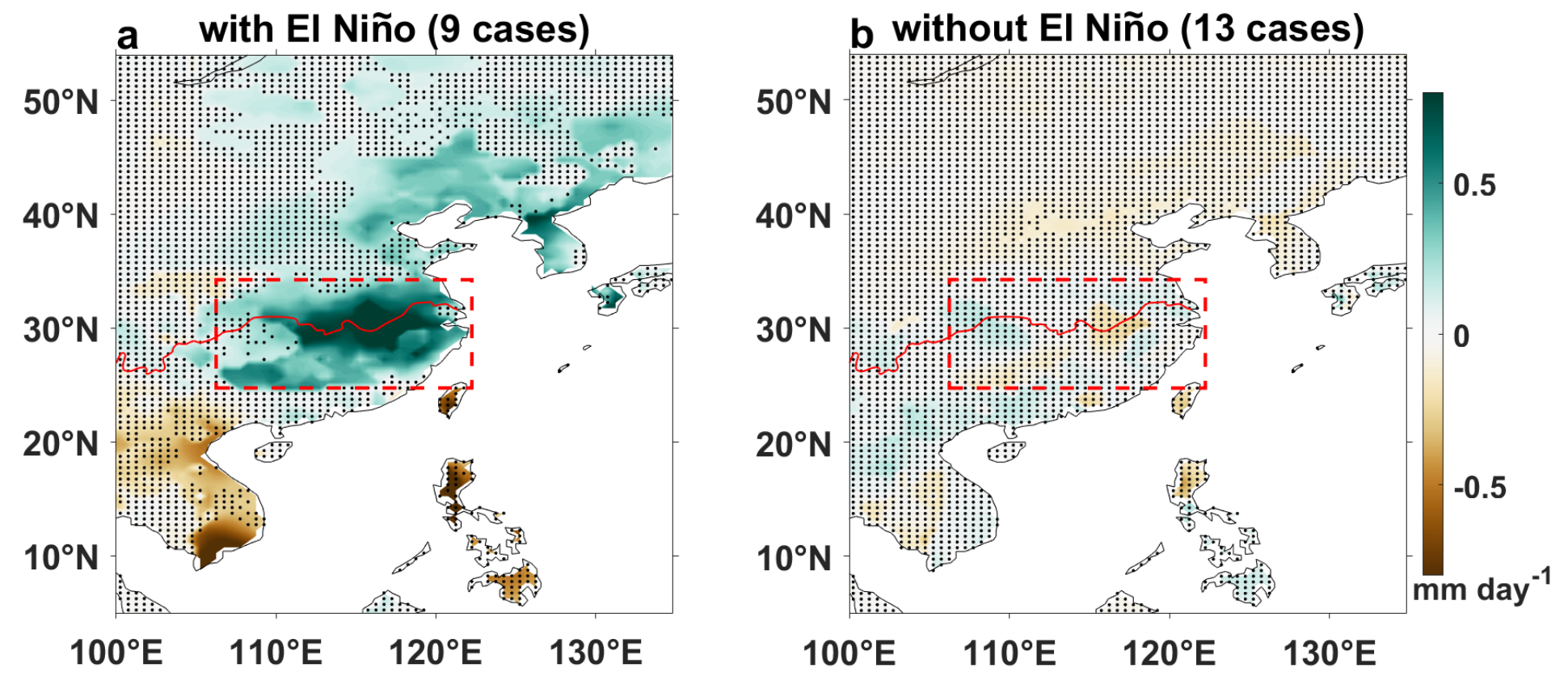
Role of El Niño in post-eruption EASM change based on reconstructions. a and b Same as Fig. 1a, except for nine tropical eruptions with and 13 eruptions without an El Niño, respectively, in the first winter after the eruption. An El Niño event is defined by the average of the 11 reconstructions of the ENSO index (see Methods).
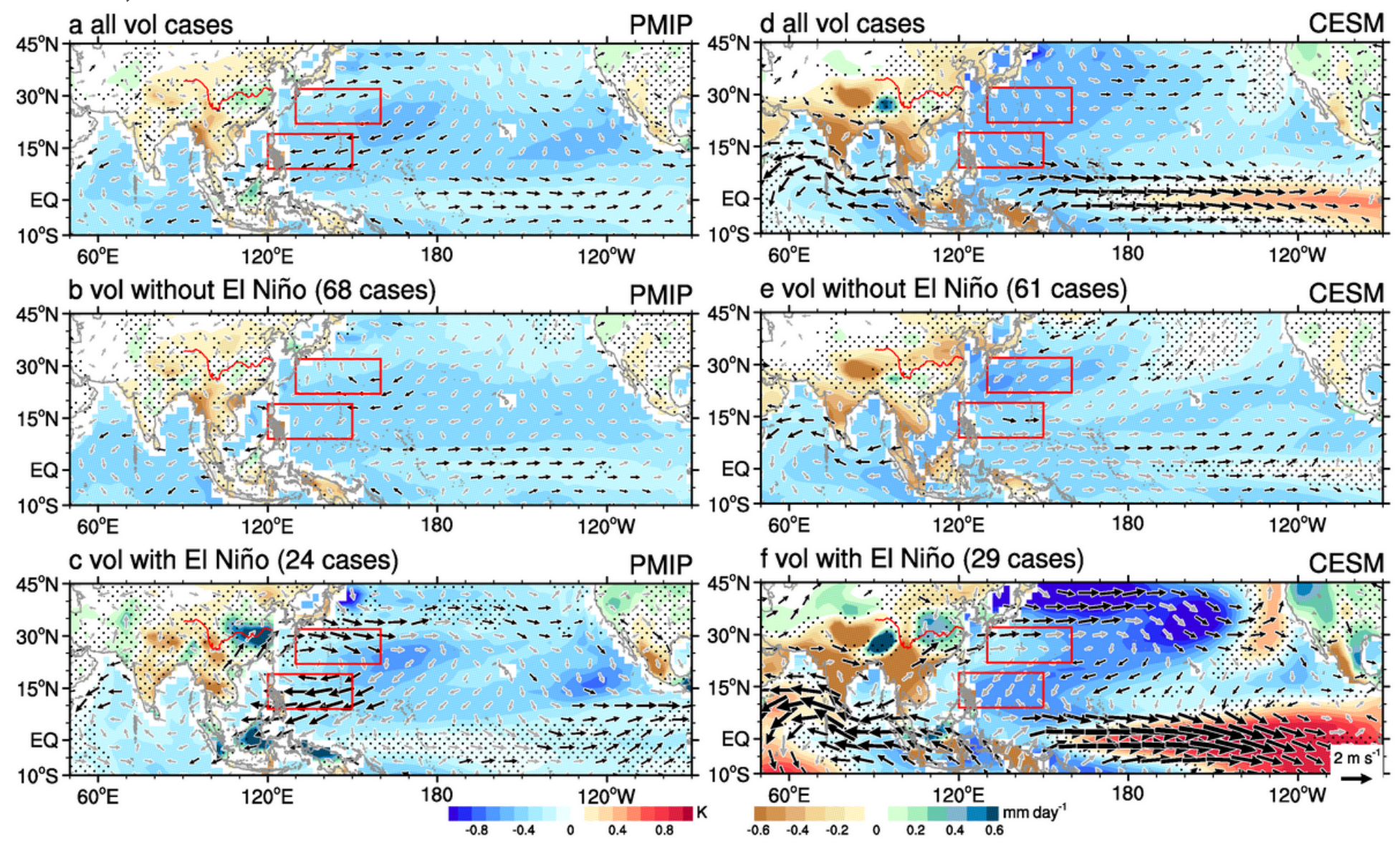

Figure 3

Simulated EASM-ocean responses to tropical eruptions. Composite SST anomalies (shading over ocean), precipitation anomalies (shading over land), and $850 \mathrm{hPa}$ wind anomalies (vectors) in the first boreal summer after a all 92 simulated tropical eruptions, b 68 eruptions without, and c 24 eruptions with an El Niño response in the first boreal winter after the eruption in 13 PMIP last millennium simulations from 1470 to 1849 AD. Stippling and grey vectors indicate precipitation and temperature anomalies and wind anomalies not significant at the $90 \%$ confidence level, respectively. The red curve is the Yangtze River. d-f Same as a-c, except for simulations in 10 CESM last-millennium full forcing ensembles from 1470 to 1999 AD. The red rectangles denote the locations where the EASM circulation index is defined: the 850 $\mathrm{hPa}$ zonal wind averaged in the southern box minus that in the northern box (see Methods). A negative value of this index represents enhanced Pacific high and associated East Asian subtropical rainfall. 


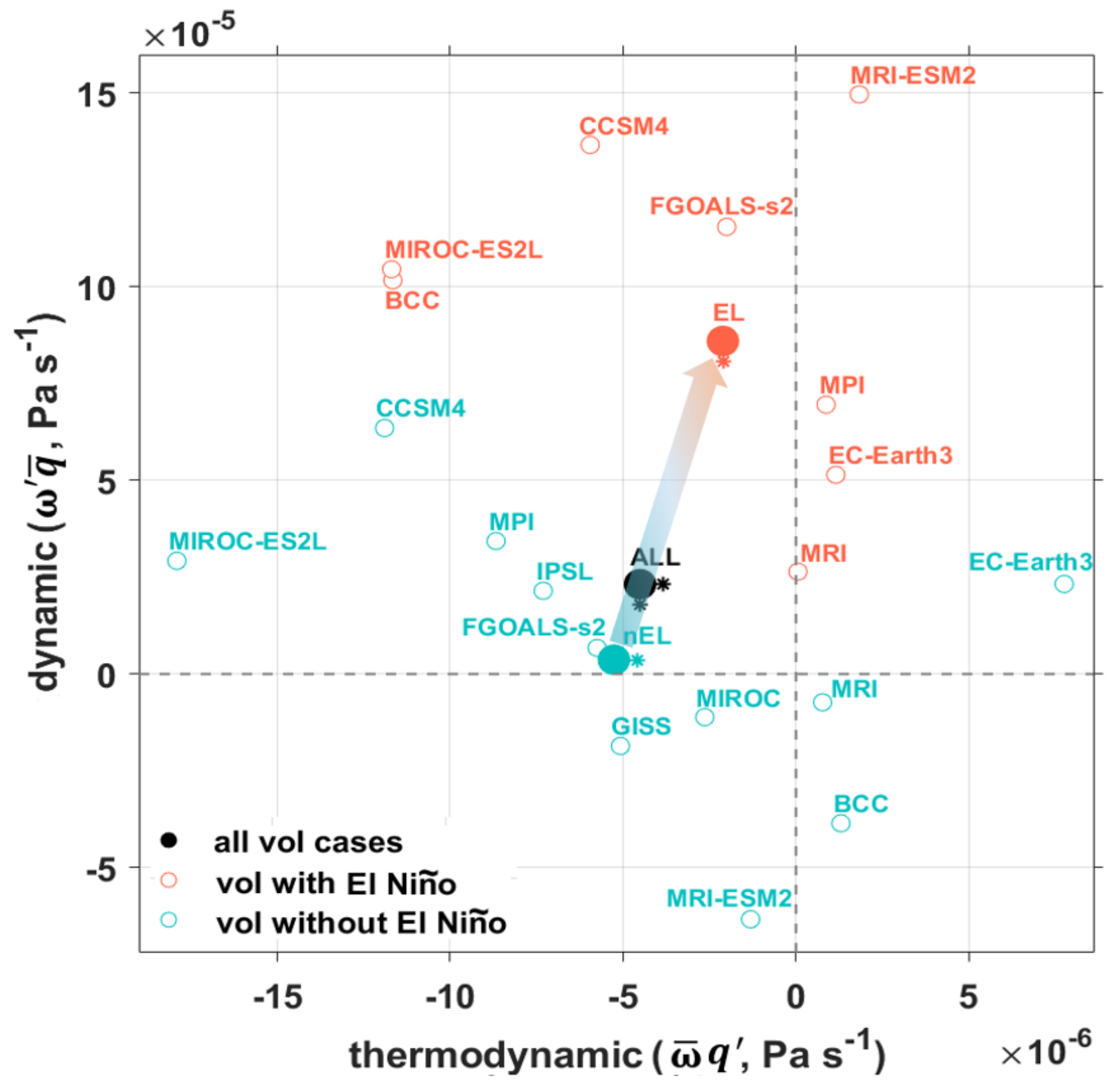

Figure 4

Simulated dynamic and thermodynamic responses of EASM to tropical eruptions modulated by El Niño. Plotted are the composite dynamic part ( $\left.\omega^{\prime} q^{-}\right)$versus thermodynamic part $\left(\omega^{-} q^{\prime}\right)$ of post-eruption EASM $\left(25^{\circ}-34^{\circ} \mathrm{N}, 106^{\circ}-122^{\circ} \mathrm{E}\right.$ ) precipitation changes after all 78 eruptions in 11 PMIP last millennium simulations from 1470 to 1849 AD (All, dark dot), as well as those of the 18 eruptions with (EL, orange dot) and 60 eruptions without (nEL, green dot) El Niño responses in the first boreal winter after eruptions. CSIRO and HadCM last millennium simulations are not included due to the lack of vertical velocity. Asterisks to the left and bottom of the dots denote the thermodynamic and dynamic anomalies significant at the $90 \%$ confidence level, respectively. The arrow indicates change from ensemble mean for 
eruptions without El Niño responses to those with El Niño responses. Results for each model are also shown by the circles. Significant test has not been performed for single models due to the small sample size of El Niño events.

\section{Supplementary Files}

This is a list of supplementary files associated with this preprint. Click to download.

- EASMSI.docx 